\title{
Isolation and characterization of genetic variability in bacteria with $\beta$-hemolytic and antifungal activity isolated from the rhizosphere of Medicago truncatula plants
}

\author{
J.E. Hernández-Salmerón ${ }^{1}$, C.M. Prieto-Barajas ${ }^{1}$, E. Valencia-Cantero ${ }^{1}$, \\ G. Moreno-Hagelsieb ${ }^{2}$ and G. Santoyo ${ }^{1}$ \\ ${ }^{1}$ Instituto de Investigaciones Químico-Biológicas, \\ Universidad Michoacana de San Nicolás de Hidalgo, \\ Morelia, Michoacán, México \\ ${ }^{2}$ Department of Biology, Wilfrid Laurier University, \\ Waterloo, Ontario, Canada \\ Corresponding autor: G. Santoyo \\ E-mail: gustavo_santoyo@yahoo.com / gsantoyo@umich.mx \\ Genet. Mol. Res. 13 (3): 4967-4975 (2014) \\ Received May 28, 2013 \\ Accepted November 1, 2013 \\ Published July 4, 2014 \\ DOI http://dx.doi.org/10.4238/2014.July.4.11
}

\begin{abstract}
In the present study, we analyzed the frequency of hemolytic and antifungal activities in bacterial isolates from the rhizosphere of Medicago truncatula plants. Of the 2000 bacterial colonies, 96 showed $\beta$-hemolytic activities (frequency, $4.8 \times 10^{-2}$ ). Hemolytic isolates were analyzed for their genetic diversity by using random amplification of polymorphic DNA, yielding 88 haplotypes. The similarity coefficient of Nei and Li showed a polymorphic diversity ranging from 0.3 to 1 . Additionally, 8 of the hemolytic isolates showed antifungal activity toward plant pathogens, Diaporthe phaseolorum, Colletotrichum acutatum, Rhizoctonia solani, and Fusarium oxysporum. The 16S ribosomal sequencing analysis showed that antagonistic bacterial isolates corresponded to Bacillus subtilis (UM15, UM33, UM42, UM49, UM52, and UM91), Bacillus pumilus (UM24), and Bacillus licheniformis
\end{abstract}


(UM88). The present results revealed a higher genetic diversity among hemolytic isolates compared to that of isolates with antifungal action.

Key words: Genetic diversity; Rhizosphere; Medicago truncatula; Hemolysis; Antifungal activity

\section{INTRODUCTION}

In the rhizosphere (the soil surrounding and influenced by the root system), plant roots secret nutrients, which are potent attractants of a wide variety of microorganisms, including those that might benefit plants' health. This microenvironment has been proposed to contain up to $10^{11}$ microbial cells per gram of soil, with a diversity of species of prokaryotes estimated at more than 30,000 (Mendes et al., 2011). In fact, the microbial communities of the rhizosphere of various plants represent a large reservoir of the known biological diversity in the world (Berendsen et al., 2012).

The microorganisms in the rhizosphere have beneficial effects on plants. In particular, many bacteria have been widely reported to exhibit such beneficial activities (Compant et al., 2005). Beneficial bacteria are known as plant growth promoting rhizobacteria or PGPR (Beneduzi et al., 2012). Although some PGPR have been used commercially, agricultural practices could benefit from a wider use because of the great potential and impact these bacteria would have on the development of sustainable agriculture, in which the use of chemical pesticides that could harm the environment and human health could be highly reduced or eliminated (Adesemoye et al., 2009; Adesemoye and Kloepper 2009). Therefore, new bacterial strains with extensive abilities to promote plant growth, either by direct or indirect mechanisms, are being continuously identified (Santoyo et al., 2012). Direct plant growth promotion mechanisms include the synthesis of phytohormones and the solubilization of nutrients to facilitate their absorption by plants (OrozcoMosqueda et al., 2013). Indirect mechanisms might include the inhibition of pathogen growth in the rhizosphere and stimulation of innate plant defenses (Beneduzi et al., 2012).

Bacillus is among the best known and the most abundant genera in the rhizosphere. Species of this genus have both direct and indirect mechanisms to improve plant growth (Santoyo et al., 2012). PGPR of this genus are known to produce various antibiotics, volatile organic compounds (VOCs), bacteriocins, and lipopeptides (Martínez-Absalón et al., 2012; Velázquez-Becerra et al., 2013). In particular, Bacillus subtilis, Bacillus amyloliquefaciens, and Bacillus thuringiensis produce several kinds of lipopeptides such as surfactin, fengicin, iturin A, bacilomicin, and mycosubtilin, which have been shown to suppress plant pathogens (Tsuge et al., 2001; Yao et al., 2003; Koumoutsi et al., 2004; Ongena and Jacques, 2008; Martínez-Absalón et al., 2012). Some lipopeptides of the iturin family exhibit strong specific antagonist activity against fungi, but their antibacterial action is limited. Some members of this family also have hemolytic activity (MagetDana and Peypoux, 1994). Mycosubtilin overproduction by B. subtilis BBG100 also increases its hemolytic activity compared with that of the wild strain. Mycosubtilin lipopeptide overexpression is also associated with an increased antifungal activity (Leclère et al., 2005). Other lipopeptides, such as surfactin produced by Bacillus spp, have also shown to have hemolytic activity (Hsieh et al., 2004). Thus, hemolytic activities are strongly associated with antifungal activities, and both activities might be exhibited by rhizospheric Bacillus strains.

To our knowledge, the frequency of bacteria with hemolytic activities in the rhizosphere isolates of any plant, as well as the proportion of hemolytic isolates with antagonistic 
action toward fungal pathogens, is unknown. Therefore, in this study, we explored the genetic diversity of hemolytic isolates from the rhizosphere of the model plant Medicago truncatula by using random amplification of polymorphic DNA or RAPD-PCR. We also determined the proportion of hemolytic isolates with antifungal activity.

\section{MATERIAL AND METHODS}

\section{Isolation of rhizospheric bacteria}

Twenty plants of $M$. truncatula, along with their roots and rhizospheric soil, were collected in Morelia, Mich. México $\left(19^{\circ} 42^{\prime} 8^{\prime \prime} \mathrm{N}, 101^{\circ} 11^{\prime} 8^{\prime \prime} \mathrm{W}\right)$. Rhizospheric soil samples were obtained at $10-\mathrm{cm}$ depth and transported on ice and stored at $4^{\circ} \mathrm{C}$ for immediate analysis in the laboratory. Rhizospheric soil ( $1 \mathrm{~g}$ ) was diluted in phosphate buffered saline (PBS) to obtain plate dilutions on nutrient agar (NA) and minimal media and incubated for 4 days at $30^{\circ} \mathrm{C}$. From these plates, 2000 colonies were randomly selected for further analysis.

\section{Hemolytic analysis}

Hemolytic activities were observed by transferring each bacterial colony by using sterile toothpicks from NA plates to blood agar plates (BAP; PROFAM, Mexico). Hemolysis was visualized by the development of a clear hemolytic halo ( $\beta$-hemolysis) around the colonies after incubation for $24 \mathrm{~h}$ at $30^{\circ} \mathrm{C}$. Rhizospheric colonies surrounded by a hemolytic halo were chosen to be replicated and to corroborate the hemolytic phenotype. Other kinds of hemolysis, including alpha and gamma, were also observed. However, previous analyses have shown that strains with these kinds of activities do not show strong antibiotic or fungitoxic action, and hence, these were excluded from further analysis (Martínez-Absalón et al., 2012).

\section{In vitro evaluation of fungitoxic activities}

Antagonistic activities against fungal phytopathogens were evaluated as previously described (Filippi et al., 1984; Santoyo et al., 2010). Briefly, the selected isolates and pathogenic fungi were simultaneously inoculated on PDA plates or NA agar plates with identical results. Isolates were streaked out on plates forming a cross and, in the center of each of the quadrants formed a mycelial plug of $4 \mathrm{~mm}$ was deposited. Plates were incubated in darkness at $30^{\circ} \mathrm{C}$, and mycelium growth was measured during 8 days. The following plant fungal pathogens were used in this study: Diaporthe phaseolorum, Colletotrichum acutatum, Rhizoctonia solani, and Fusarium oxysporum, which were routinely maintained on PDA media at $4^{\circ} \mathrm{C}$.

\section{DNA extraction}

Total DNA was extracted by using routine molecular biology protocols (Sambrook et al., 1982) from 96 selected rhizospheric soil isolates with hemolytic activity, as well as from reference strains, including Sinorhizobium meliloti, Rhizobium sp. NGR234, Pseudomonas aeruginosa PAO1, Stenotrophomonas maltophilia, Bacillus megaterium, and Arthrobacter luteus. The extracted DNA solution was checked by gel electrophoresis and stained with ethidium bromide. 


\section{RAPD analysis}

For the RAPD technique, 3 different primers were initially used, but the Opa02 primer (GTTTCCGCCC) showed the best results allowing the differentiation of various isolates. The following PCR conditions were used: 35 cycles, $94^{\circ} \mathrm{C}$ for $1 \mathrm{~min}, 38^{\circ} \mathrm{C}$ for $1 \mathrm{~min}, 72^{\circ} \mathrm{C}$ for 1 min. After the PCR products of the 96 isolates and reference strains were obtained, a matrix with data of presence/absence of bands according to molecular size was created. For the construction of the dendrogram, the multivariate statistical package program was used (Kovach, 1999), supported with the similarity coefficient proposed by Nei and Li (1979).

\section{Molecular typing and phylogenetic analysis}

Molecular typing and phylogenetic analyses were carried out as previously described (Martínez-Absalón et al., 2012). Genomic DNA was isolated from 8 antagonistic isolates (UM15, UM24, UM33, UM42, UM49, UM52, UM88, and UM91) to amplify by PCR (Sambrook et al., 1982) the ribosomal 16S rRNA gene by using the universal bacterial primers Fd1, 5'-CAGAGTTTGATCCTGGCTCAG-3' and Rd1, 5'-AAGGAGGTGATCCAGCC-3' (Weisburg et al., 1991). PCR conditions were used as follows: an initial denaturation at $95^{\circ} \mathrm{C}$ for 3 min; 30 cycles of $1 \mathrm{~min}$ at $95^{\circ} \mathrm{C}$ for denaturation, $1 \mathrm{~min}$ at $53^{\circ} \mathrm{C}$ for annealing, and $2 \mathrm{~min}$ at $72^{\circ} \mathrm{C}$ for extension; and a final extension step at $72^{\circ} \mathrm{C}$ for $5 \mathrm{~min}$. PCR amplifications were performed using a TC-412 Techne Thermal Cycler. GoTaq ${ }^{\circledR}$ Master Mixes tubes (Promega) (tubes contain enzyme, magnesium, dNTPs, and buffer). Only $0.1 \mu \mathrm{g}$ template DNA and 50 pmol each primer were added to each tube. The PCR product was additionally purified using the Wizard ${ }^{\mathbb{B}}$ SV Gel and PCR Clean-Up System (Promega), according to manufacturer instructions. The rRNA 16S gene from bacterial isolate UM96 was sequenced at the Laboratorio Nacional para la Diversidad Genómica, CINVESTAV-Irapuato, Mexico. The ribosomal sequences obtained were compared with those deposited in the GenBank (NCBI) database by using the BLASTN program.

Phylogenetic analysis of the 16S rRNA gene sequences was carried out using the MEGA 4.0 program (Tamura et al., 2007). A confidence value for the aligned sequence dataset was obtained by performing bootstrap analysis of 1000 replications. A phylogenetic tree was constructed using the maximum likelihood.

\section{RESULTS}

\section{Frequency of hemolytic isolates from M. truncatula rhizosphere}

In all, 2000 rhizospheric isolates were isolated on rich and poor nutrient media from M. truncatula plants. Of these, 96 showed a clear hemolytic halo (beta-hemolysis) around the colony. This indicates that the frequency of detectable hemolytic activity in isolates from the rhizosphere of M. truncatula plants was $4.8 \times 10^{-2}$.

\section{Hemolytic isolates show high genetic diversity}

Since hemolytic activities have been found in several species, we evaluated the genetic diversity of the 96 selected isolates by using the RAPD technique (Figure 1). These analyses 
detected 88 different haplotypes and, according to the Nei and Li coefficient, these isolates showed a genetic diversity ranging from 0.3 to 1 , which could correspond to diverse bacterial species (Figure 2). Interestingly, the dendrogram and similarity coefficients did not allow the detection of groups or clusters of bacteria, but only some specific or repeated haplotypes were detected, which were clearly grouped with some reference strains such as Bacillus megaterium.

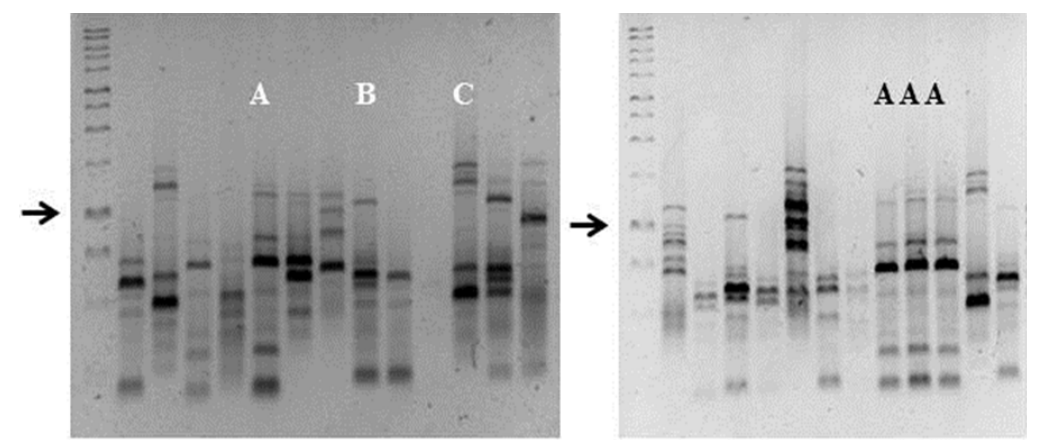

Figure 1. Representative examples of RAPD-PCR typing of diverse hemolytic isolates analyzed with the OPA2 primer. Six antifungal strains are also included and marked with letters A (UM15, UM33, UM42, UM49), B (UM24) and C (UM88). Pattern reproducibility was checked by at least duplicate analysis.

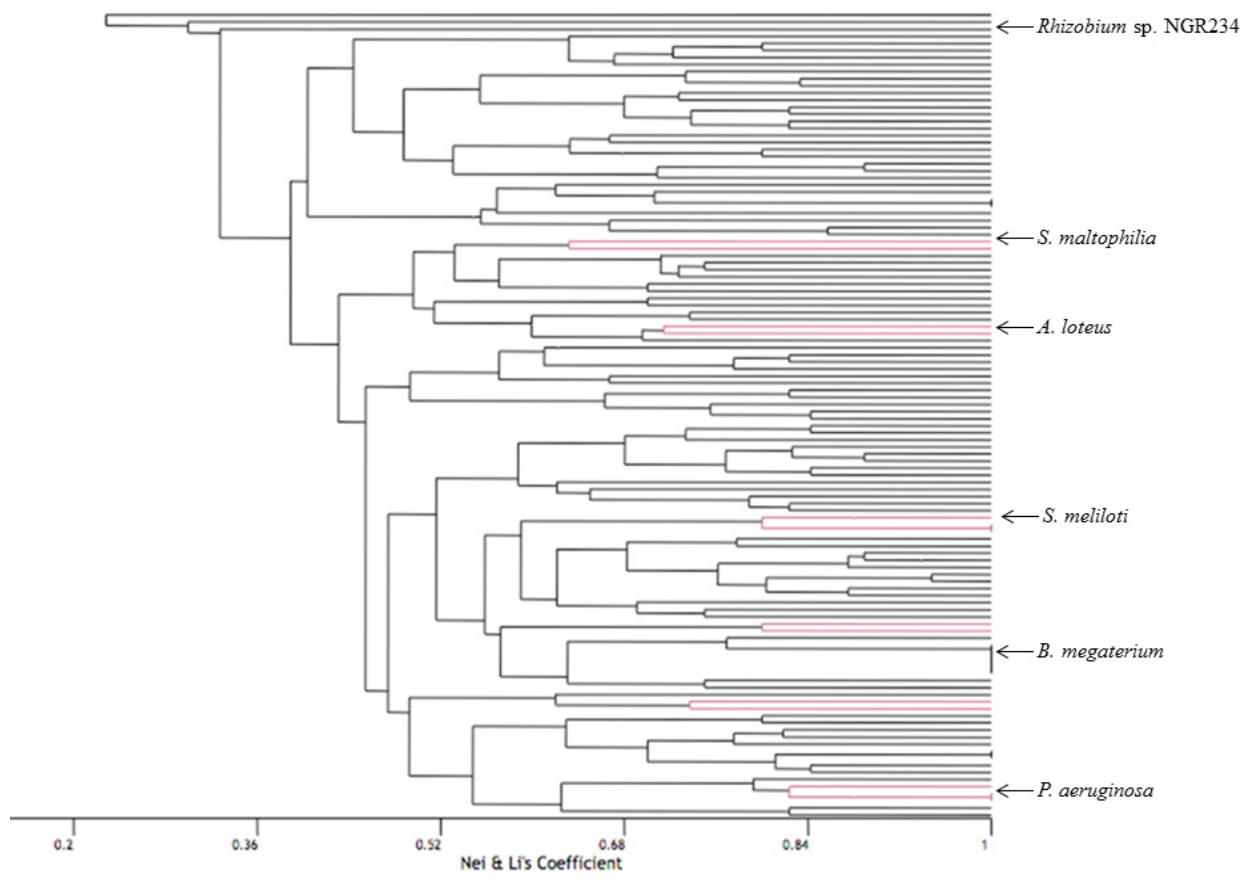

Figure 2. RAPD dendrogram showing genetic diversity similarity of 96 hemolytic isolates of Medicago truncatula rhizosphere. Position of reference strains are also marked (Sinorhizobium meliloti, Rhizobium sp NGR234, Pseudomonas aeruginosa PAO1, Stenotrophomonas maltoplilia, Bacillus megaterium, and Arthrobacter luteus). MVSP was used to construct a dendrogram based on the similarity coefficient of Nei and Li (1979). 


\section{Frequency of antifungal isolates from $M$. truncatula rhizosphere}

Since hemolysis has been associated with antibiotic production, we evaluated the frequency of fungal antagonism among those hemolytic isolates. Of the 96 hemolytic isolates, 8 exhibited mycelial growth inhibition against 4 phytopathogens, Diaporthe phaseolorum, Colletotrichum acutatum, Rhizoctonia solani, and Fusarium oxysporum. The inhibition strengths were different among the isolates, with UM15 and UM24 strains exhibiting wider zones of growth inhibition. Strains UM42, UM49, and UM52 showed antagonism against only one of these phytopathogens (Table 1).

Table 1. Fungal inhibition grades of hemolytic bacterial isolates from Medicago truncatula rhizosphere.

\begin{tabular}{|c|c|c|c|c|c|c|c|c|}
\hline \multirow[t]{2}{*}{ Bacterial isolate } & \multicolumn{8}{|c|}{ Bacterial isolate } \\
\hline & UM15 & UM24 & UM33 & UM42 & UM49 & UM52 & UM88 & UM91 \\
\hline Diaporthe phaseolorum & + & ++ & + & - & + & ++ & + & + \\
\hline Colletotrichum acutatum & ++ & + & - & - & - & - & - & + \\
\hline Rhizoctonia solani & +++ & + & + & + & - & - & + & - \\
\hline Fusarium oxysporum & ++ & +++ & ++ & - & - & - & + & + \\
\hline
\end{tabular}

(-) No inhibition zone, $(+)$ Inhibition zone $\leq 0.5 \mathrm{~mm},(++)$ Inhibition zone $\leq 1 \mathrm{~mm},(+++)$ Inhibition zone $\geq 1.5$ $\mathrm{mm}$. Fungal growth inhibition is presented as the mean of at least three replicates measured in millimeters (mm) of diameter of mycelium growth.

\section{Bacterial isolates with hemolytic and fungitoxic activity belong to Bacillus species}

The 16S rRNA gene from the strains showing antagonistic activity was isolated and sequenced. BLAST searches against the NCBI databases showed a high identity (98-99\%) with Bacillus strains, corresponding to B. subtilis (UM15, UM33, UM42, UM49, UM52, and UM91), Bacillus pumilus (UM24), and Bacillus licheniformis (UM88). These results corroborated with the phylogenetic analyses between the antagonistic strains and their respective $\mathrm{Ba}$ cillus species relatives (Figure 3).

\section{DISCUSSION}

Hemolytic activities have been observed in different bacterial genera, including species of the genus Bacillus, such as B. subtilis, B. circulans, B. thuringiensis, B. cereus, and B. amyloliquefaciens. Some hemolytic activities have been detected in strains producing antibiotic compounds such as bacteriocins, iturin A, surfactin, or mycosubtilin (Hsieh et al., 2004; Leclère et al., 2005). The specific mechanisms of these antibiotics are diverse, but the formation of pores in erythrocytes, as well as in bacterial or fungal cell walls, is a predominant mechanism (Maget-Dana and Peypoux, 1994). Therefore, strains producing these kinds of antibiotics contain an excellent activity to inhibit the growth of competitors in ecosystems like the rhizosphere. Thus, the production of several lipopeptides such as mycosubtilin, iturin, or surfactin has been associated with the inhibition or biocontrol of different fungal plant pathogens (Leclère et al., 2004).

Recently (Martínez-Absalón et al., 2012), a strain of Bacillus sp (UM96) was isolated, and its antifungal and hemolytic activities were characterized. Such strains showed strong 
inhibition against the same fungal phytopathogens analyzed in this study. The supernatant of the UM96 strain also showed strong hemolytic activity, which was not observed in the supernatant treated with protease. However, the supernatant that was treated with protease had antagonistic effects similar to those exhibited by the supernatant that was not treated with the enzyme. A bacteriocin-like compound is thought to be responsible for the hemolytic activity, while a lipopeptide might be causing the antifungal effect. The above evidence indicates that the different grades of inhibition shown by antagonistic strains isolated in this study could be due to the synthesis of diverse kinds of antibiotics. Experiments are in progress to determine the specific mechanism.

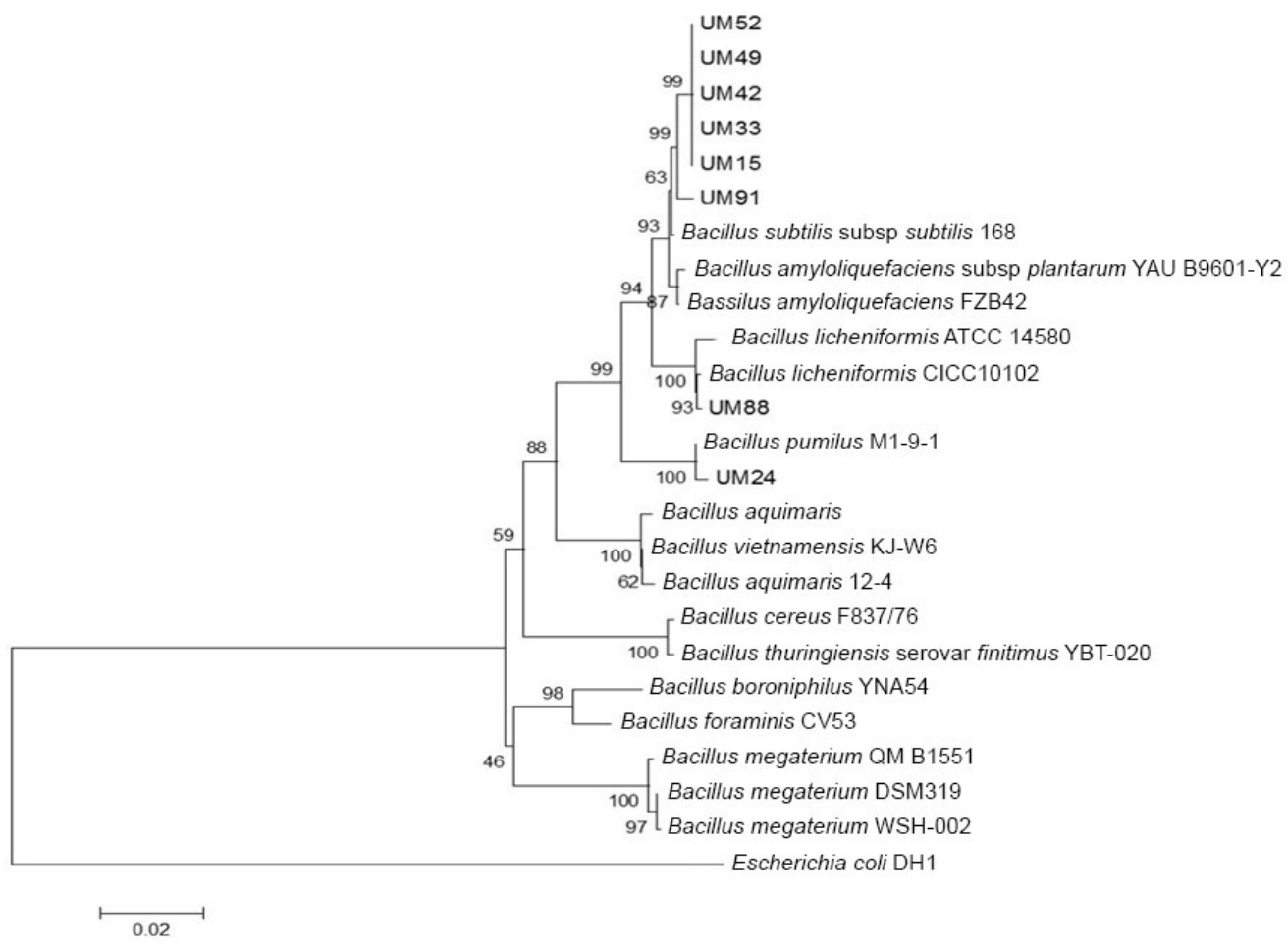

Figure 3. Phylogenetic tree based on $16 \mathrm{~S}$ ribosomal gene sequences showing the relationship between Bacillus subtilis strains UM15, UM33, UM42, UM49, UM52, UM91, Bacillus pumilus UM24 and Bacillus licheniformis UM88 with other Bacillus species. The phylogenetic tree was constructed using the Maximum Likelihood algorithm. Bootstrap analysis of 1000 replications was performed and is expressed as percentage. Listeria innocua was used as outgroup.

In this study, we isolated 8 Bacillus strains that exhibited good antagonistic activities against 4 worldwide dispersed plant pathogens (Diaporthe phaseolorum, Colletotrichum acutatum, Rhizoctonia solani, and Fusarium oxysporum), which cause drastic economic losses in many agricultural fields. These Bacillus strains should be further evaluated to determine the specific production of lipopeptides or other antibiotics responsible of fungal growth inhibition, especially the strains $B$. subtilis UM15 and UM33, which showed the best inhibition against the 4 fungi tested here. Diverse strains of $B$. subtilis have shown strong antagonism 
toward plant pathogens, and novel strains are also emerging as potential biocontrol agents (Santoyo et al., 2012). Additionally, the frequencies of antifungal strains in the rhizosphere of M. truncatula plants are in agreement with other results showing that 1 to $2 \%$ of bacteria in the rhizosphere promote plant growth by diverse mechanisms (Antoun and Kloepper, 2001).

Diverse bacterial species, including plants, animals, or human pathogens, have the capacity to lysate erythrocytes as a mechanism to invade the host cells or defend from the immune system (Tabata et al., 2013). Hence, since a high genetic diversity was observed among the bacterial hemolytic strains isolated from the rhizosphere of M. truncatula plants, the different haplotypes found could possibly correspond to different and very diverse bacterial taxa. A detailed analysis of the taxa of all the hemolytic strains could reveal whether other pathogenic strains reside in the rhizosphere ecosystem, although it is known that potential human or animal pathogens can reside in this habitat (Berg et al., 2005). However, interestingly, all the 8 strains with hemolytic and fungal inhibitory activity isolated in this study corresponded to non-potential human or animal pathogens, but showed high identity to common rhizosphereresident Bacillus species.

\section{ACKNOWLEDGMENTS}

We thank Consejo Nacional de Ciencia y Tecnología, México (Project: \#169346) and Coordinación de la Investigación Científica-Universidad Michoacana de San Nicolás de Hidalgo (Project: \#2012-2013) for financial support to this research. J.E. Hernández-Salmerón received doctoral fellowship from Consejo Nacional de Ciencia y Tecnología, México.

\section{REFERENCES}

Adesemoye AO and Kloepper JW (2009). Plant-microbes interactions in enhanced fertilizer-use efficiency. Appl. Microbiol. Biotechnol. 85: 1-12.

Adesemoye AO, Torbert HA and Kloepper JW (2009). Plant growth-promoting rhizobacteria allow reduced application rates of chemical fertilizers. Microb. Ecol. 58: 921-929.

Antoun H and Kloepper JW (2001). Plant Growth Promoting Rhizobacteria. (Brenner S and Miller JH, eds.). Encyclopedia of Genetics Academic, New York, 1477-1480.

Beneduzi A, Ambrosini A and Passaglia LM (2012). Plant growth-promoting rhizobacteria (PGPR): Their potential as antagonists and biocontrol agents. Genet. Mol. Biol. 35: 1044-1051.

Berendsen RL, Pieterse CM and Bakker PA (2012). The rhizosphere microbiome and plant health. Trends Plant Sci. 17: 478-486.

Berg G, Eberl L and Hartmann A (2005). The rhizosphere as a reservoir for opportunistic human pathogenic bacteria. Environ. Microbiol. 7: 1673-1685.

Compant S, Duffy B, Nowak J, Clement C, et al. (2005). Use of plant growth-promoting bacteria for biocontrol of plant diseases: principles, mechanisms of action, and future prospects. Appl. Environ. Microbiol. 71: 4951-4959.

Filippi C, Bagnoli G, Treggi G and Picci G (1984). Antagonistic effects of soil bacteria on Fusarium oxysporum Schlecht f. sp. Dianthii (Print and Del.) Snyd and Hans I. In vitro experiments and preliminary assays on Carnation (Dianthus caryophyllus L.). Plant and Soil 80: 119-125.

Hsieh FC, Li MC, Lin TC and Kao SS (2004). Rapid detection and characterization of surfactin-producing Bacillus subtilis and closely related species based on PCR. Curr. Microbiol. 49: 186-191.

Koumoutsi A, Chen XH, Henne A, Liesegang H, et al. (2004). Structural and functional characterization of gene clusters directing nonribosomal synthesis of bioactive cyclic lipopeptides in Bacillus amyloliquefaciens strain FZB42. J. Bacteriol. 186: 1084-1096.

Kovach WL (1999). MVSP - a multivariate statistical package for windows, ver. 3.1. Kovach Computing Services, Pentraeth, Wales, Great Britain, 133.

Leclère V, Béchet M, Adam A, Guez JS, et al. (2005). Mycosubtilin overproduction by Bacillus subtilis BBG100 enhances 
the organism's antagonistic and biocontrol activities. Appl. Environ. Microbiol. 71: 4577-4584.

Maget-Dana R and Peypoux F (1994). Iturins, a special class of pore-forming lipopeptides: biological and physicochemical properties. Toxicology 87: 151-174.

Martínez-Absalón SC, del C Orozco-Mosqueda M, Martínez-Pacheco MM, Farías-Rodríguez R, et al. (2012). Isolation and molecular characterization of a novel strain of Bacillus with antifungal activity from the sorghum rhizosphere. Genet. Mol. Res. 11: 2665-2673.

Mendes R, Kruijt M, de B, I, Dekkers E, et al. (2011). Deciphering the rhizosphere microbiome for disease-suppressive bacteria. Science 332: 1097-1100.

Nei M and Li WH (1979). Mathematical model for studying genetic variation in terms of restriction endonucleases. Proc. Natl. Acad. Sci. U. S. A. 76: 5269-5273.

Ongena M and Jacques P (2008). Bacillus lipopeptides: versatile weapons for plant disease biocontrol. Trends Microbiol. 16: $115-125$.

Orozco-Mosqueda MC, Velázquez-Becerra C, Macías-Rodríguez LI, Santoyo G, et al. (2013). Arthrobacter agilis UMCV2 induces iron acquisition in Medicago truncatula (Strategy I plant) in vitro via dimethylhexadecylamine emission. Plant Soil 362: 51-66.

Sambrook J, Frisch EF and Maniatis T (1982). Molecular Cloning: a Laboratory Manual. Cold Spring Harbor Laboratory Press, Cold Spring Harbor, New York.

Santoyo G, Valencia-Cantero E, Orozco-Mosqueda Ma del C, Peña-Cabriales JJ, et al. (2010). Papel de los sideróforos en la actividad antagónica de Pseudomonas fluorescens ZUM80 hacia hongos fitopatógenos. Terra Latinoam. 28: 53-60.

Santoyo G, Orozco-Mosqueda Ma del C and Govindappa M (2012). Mechanisms of biocontrol and plant growth-promoting activity in soil bacterial species of Bacillus and Pseudomonas: a review. Biocontrol. Sci. Technol. 22: 855-872.

Tabata A, Nakano K, Ohkura K, Tomoyasu T, et al. (2013). Novel twin streptolysin S-like peptides encoded in the sag operon homologue of beta-hemolytic Streptococcus anginosus. J. Bacteriol. 195: 1090-1099.

Tamura K, Dudley J, Nei M and Kumar S (2007). MEGA4: Molecular Evolutionary Genetics Analysis (MEGA) software version 4.0. Mol. Biol. Evol. 24: 1596-1599.

Tsuge K, Akiyama T and Shoda M (2001). Cloning, sequencing, and characterization of the iturin A operon. J. Bacteriol. 183: 6265-6273.

Velázquez-Becerra C, Macías-Rodríguez LI, López-Bucio J, Flores-Cortez I, et al. (2013). The rhizobacterium Arthrobacter agilis produces dimethylhexadecylamine, a compound that inhibits growth of phytopathogenic fungi in vitro. Protoplasma 250: 1251-1262.

Weisburg WG, Barns SM, Pelletier DA and Lane DJ (1991). 16S ribosomal DNA amplification for phylogenetic study. J. Bacteriol. 173: 697-703.

Yao S, Gao X, Fuchsbauer N, Hillen W, et al. (2003). Cloning, sequencing, and characterization of the genetic region relevant to biosynthesis of the lipopeptides iturin A and surfactin in Bacillus subtilis. Curr. Microbiol. 47: 272-277. 